DIGITALCOMMONS

—@WAYNESTATE-

Journal of Modern Applied Statistical Methods

Volume 11 | Issue 1

Article 8

5-1-2012

\title{
Comparison of Re-sampling Methods to Generalized Linear Models and Transformations in Factorial and Fractional Factorial Designs
}

Maher Qumsiyeh

University of Dayton

Gerald Shaughnessy

University of Dayton, Ohio

Follow this and additional works at: http://digitalcommons.wayne.edu/jmasm

Part of the Applied Statistics Commons, Social and Behavioral Sciences Commons, and the Statistical Theory Commons

\section{Recommended Citation}

Qumsiyeh, Maher and Shaughnessy, Gerald (2012) "Comparison of Re-sampling Methods to Generalized Linear Models and Transformations in Factorial and Fractional Factorial Designs," Journal of Modern Applied Statistical Methods: Vol. 11 : Iss. 1 , Article 8. DOI: $10.22237 /$ jmasm/1335845220

Available at: http://digitalcommons.wayne.edu/jmasm/vol11/iss1/8

This Regular Article is brought to you for free and open access by the Open Access Journals at DigitalCommons@WayneState. It has been accepted for inclusion in Journal of Modern Applied Statistical Methods by an authorized editor of DigitalCommons@WayneState. 


\title{
Comparison of Re-sampling Methods to Generalized Linear Models and Transformations in Factorial and Fractional Factorial Designs
}

\author{
Maher Qumsiyeh Gerald Shaughnessy \\ University of Dayton, \\ Dayton $\mathrm{OH}$
}

Experimental situations in which observations are not normally distributed frequently occur in practice. A common situation occurs when responses are discrete in nature, for example counts. One way to analyze such experimental data is to use a transformation for the responses; another is to use a link function based on a generalized linear model (GLM) approach. Re-sampling is employed as an alternative method to analyze non-normal, discrete data. Results are compared to those obtained by the previous two methods.

Key words: Factorial experiments, fractional factorial experiments, effect estimation, confidence intervals.

\begin{abstract}
Introduction
Transformation, generalized linear model (GLM) and bootstrap (re-sampling) are methods employed to examine data when systematic and error assumptions may not hold; this suggests a need for inference procedures which are not based on ordinary least squares. Montgomery and Myers (1997) used a GLM approach to analyze data from research conducted by Bisgaard and Fuller (1994) where the response variable was a count of the number of defects in car grille opening panels; they concluded that using GLMs will provide shorter confidence intervals for the mean predicted response compared to those obtained using transformations. This study shows that this is not necessarily true: it depends on the type of data at hand.
\end{abstract}

Benski (1994) compared nine different techniques to determine active factors. Qumsiyeh and Shaughnessy (2008) showed that

Maher Qumsiyeh is an Assistant Professor in the Department of Mathematics. Email him at: qumsiyeh@udayton.edu. Gerald Shaughnessy is a Professor Emeritus in the Department of Mathematics. Email him at: gshaughnessy1@udayton.edu. the bootstrap (re-sampling) could be used to determine the active factors (factors that have an effect on the response) without any requirements on the type of data provided. This study shows that this method of determining active factors agrees with other methods, such as the halfnormal plots, in addition this study shows how this method can be used to obtain confidence intervals for responses after determining active factors.

The bootstrap has been shown to provide better than normal estimates of distribution functions of studentized statistics (see Singh, 1981; Bickle \& Freedman, 1980; Babu \& Singh 1983; Babu and Singh 1984). Qumsiyeh (1994) demonstrated that bootstrap approximation for the distribution of the studentized least square estimate is asymptotically better, not only than the normal approximation, but also than the two-term Edgeworth expansion. Lahiri (1992) showed the superiority of the bootstrap for approximating the distribution of M-estimators. Bhattacharya and Qumsiyeh (1989) conducted an $\mathrm{L}^{\mathrm{p}}$ comparison between the bootstrap and Edgeworth expansions. Finally, Qumsiyeh and Shaughnessy (2010) showed that the bootstrap can be used to determine the active factors in two level designs with missing responses. 


\section{COMPARISON OF RE-SAMPLING METHODS}

\section{The Data}

The data consist of three examples taken from the literature, the first two are fractional factorial and the third is full factorial. The third example presents data that can be analyzed using ordinary least squares. Results obtained were compared with results obtained using ordinary least squares.

\section{Box, Hunter and Hunter}

Box, Hunter and Hunter (1978) presented an example where the response $Y_{1}$ is the glossiness of car paint measured as counts on a scale of 1 to 100; this measure depended on the setting of 8 factors and sixteen readings were taken, thus, it is part of a $2^{8-4}$ fractional factorial design. The first four factors are listed in standard order, other factors have the alias structure: $\mathrm{E}=\mathrm{ABC}, \mathrm{F}=\mathrm{ABD}, \mathrm{G}=\mathrm{ACD}, \mathrm{H}=\mathrm{BCD}$. Using normal plots, factors $\mathrm{A}$ and $\mathrm{B}$ appear to be the active factors. Using the transformation

$$
Y=\left(\sqrt{Y_{1}}+\sqrt{Y_{1}+1}\right) / 2
$$

the final model for the transformed responses is:

$$
\widehat{Y}=8.04+0.5173^{*} \mathrm{~A}+0.3916^{*} \mathrm{~B} .
$$

Bisgaard and Fuller

Bisgaard and Fuller (1994) presented an example of a $2^{9-5}$ fractional factorial. The response $\mathrm{Y}_{2}$ is the number of defects in the finish of sheet molded grille opening panels. The first four factors are listed in the standard order. Other factors have the alias structure: $E=B D$, $\mathrm{F}=\mathrm{BCD}, \mathrm{G}=\mathrm{AC}, \mathrm{H}=\mathrm{ACD}, \mathrm{J}=\mathrm{AB}$. Using the transformation

$$
Y=\left(\sqrt{Y_{2}}+\sqrt{Y_{2}+1}\right) / 2
$$

as well as normal plots, Bisgaard and Fuller determined that the final model for the transformed responses is:

$$
\widehat{Y}=2.513-0.996^{*} \mathrm{D}-1.21 * \mathrm{~F}-0.772 * \mathrm{BG},
$$

where $\mathrm{D}, \mathrm{F}=\mathrm{BCD}$ and $\mathrm{BG}=\mathrm{ABC}$ are the active factors.

Walpole and Myers

In this third example, the data are from a study to determine factors that influence the shrinkage of molded parts. The response variable $\mathrm{Y}_{3}$ is the deviation from nominal shrinkage in $\mathrm{cm} \times 10^{4}$ and it is part of a $2^{4}$ full factorial design. This example is from Walpole and Myers (1993) and differs from the other two examples, because ordinary least squares can be applied to this data without the need for transformation. Using the half-normal plot, it was determined that factors $\mathrm{A}, \mathrm{B}$ and the $\mathrm{AB}$ interaction are the active factors and the final model is:

$$
\widehat{Y}_{3}=80+5.28^{*} \mathrm{~A}+6.22 * \mathrm{~B}+5.70 * \mathrm{AB} .
$$

The experimental grid for the three examples is shown in Table 1 and the half-normal plots for the three examples are shown in Table 2. In Table 2, based on the normal plots, it is clear that factors $\mathrm{A}$ and $\mathrm{B}$ are the active factors for the first data set, factors $\mathrm{A}, \mathrm{B}$ and the $\mathrm{AB}$ interaction are the active factors for the third data set and for the second data set $\mathrm{D}$ and $\mathrm{F}$ and the two factor interaction $\mathrm{GH}$ are active.

Bootstrap Method to Determine Active Factors The bootstrap method can be used, without need for transformation, to determine the active factors (that is, factors that have an effect on the response) and provide models similar to equations (1), (2) and (3). The bootstrap can also be used to provide confidence intervals for the size of the effect. The procedure is as follows: Assume a data set has $\mathrm{N}$ total responses (16 in the examples provided). In order to test whether some factor, for example Z, is active ( $Z$ could be the interaction of other factors):

1) Sample $N / 2$ responses with replacement from the data at the $(+1)$ level of the factor Z. 


\section{QUMSIYEH \& SHAUGHNESSY}

Table 1: Experimental Grid for Examples

\begin{tabular}{|c|c|c|c|c|c|c|c|}
\cline { 2 - 8 } \multicolumn{1}{c|}{} & $\mathrm{A}$ & $\mathrm{B}$ & $\mathrm{C}$ & $\mathrm{D}$ & $\mathrm{Y}_{1}$ & $\mathrm{Y}_{2}$ & $\mathrm{Y}_{3}$ \\
\hline$(-)$ & -1 & -1 & -1 & -1 & 53 & 56 & 72.68 \\
\hline $\mathrm{A}$ & 1 & -1 & -1 & -1 & 60 & 17 & 71.74 \\
\hline $\mathrm{B}$ & -1 & 1 & -1 & -1 & 68 & 2 & 76.09 \\
\hline $\mathrm{AB}$ & 1 & 1 & -1 & -1 & 78 & 4 & 93.19 \\
\hline $\mathrm{C}$ & -1 & -1 & 1 & -1 & 48 & 3 & 71.25 \\
\hline $\mathrm{AC}$ & 1 & -1 & 1 & -1 & 67 & 4 & 70.59 \\
\hline $\mathrm{BC}$ & -1 & 1 & 1 & -1 & 55 & 50 & 70.92 \\
\hline $\mathrm{ABC}$ & 1 & 1 & 1 & -1 & 78 & 2 & 104.96 \\
\hline $\mathrm{D}$ & -1 & -1 & -1 & 1 & 49 & 1 & 73.52 \\
\hline $\mathrm{AD}$ & 1 & -1 & -1 & 1 & 68 & 0 & 75.97 \\
\hline $\mathrm{BD}$ & -1 & 1 & -1 & 1 & 61 & 3 & 74.28 \\
\hline $\mathrm{ABD}$ & 1 & 1 & -1 & 1 & 81 & 12 & 92.87 \\
\hline $\mathrm{CD}$ & -1 & -1 & 1 & 1 & 52 & 3 & 79.34 \\
\hline $\mathrm{ACD}$ & 1 & -1 & 1 & 1 & 70 & 4 & 75.12 \\
\hline $\mathrm{BCD}$ & -1 & 1 & 1 & 1 & 65 & 0 & 79.67 \\
\hline $\mathrm{ABCD}$ & 1 & 1 & 1 & 1 & 82 & 0 & 97.8 \\
\hline
\end{tabular}

2) Sample $N / 2$ responses with replacement at the $(-1)$ level of the factor $Z$.

3) Estimate the effect of that factor using the difference between the average at the $(+1)$ level and (-1) levels.

4) Repeat the sampling procedure a large number of times, for example, 500 .

5) Take the average of the differences of the averages at the +1 level and -1 levels across the 500 samples: this is the effect size estimate.

6) Determine the upper $(1-\alpha / 2)$ and lower $\alpha / 2$ percentile points of the re-sampled effect values.

7) Use these values to construct the $(1-\alpha)$ $\mathrm{x} 100 \%$ confidence interval for the effect size.
8) If the confidence interval does not contain zero then the factor is identified as an active factor.

The mean effect size and confidence intervals for the different effect sizes for the three different examples were determined using this procedure (see Table 3 ).

Table 3 shows the LCL (2.5 percentile lower confidence limit) and UCL (97.5 percentile upper confidence limit). The only confidence intervals that do not contain zero in the first example are those of $\mathrm{A}$ and $\mathrm{B}$, this matches the results of the normal plots and Box, Hunter and Hunter. In addition, the only confidence intervals that do not contain zero in the third example are those of $\mathrm{A}, \mathrm{B}$ and the $\mathrm{AB}$ interaction, this matches the results of the halfnormal plots and of Walpole and Myers. With respect to the second example, the only confidence intervals that do not contain zero are those of D and F. The two-factor interaction BG 
COMPARISON OF RE-SAMPLING METHODS

Table 2: Half-Normal Plots for the Three Examples

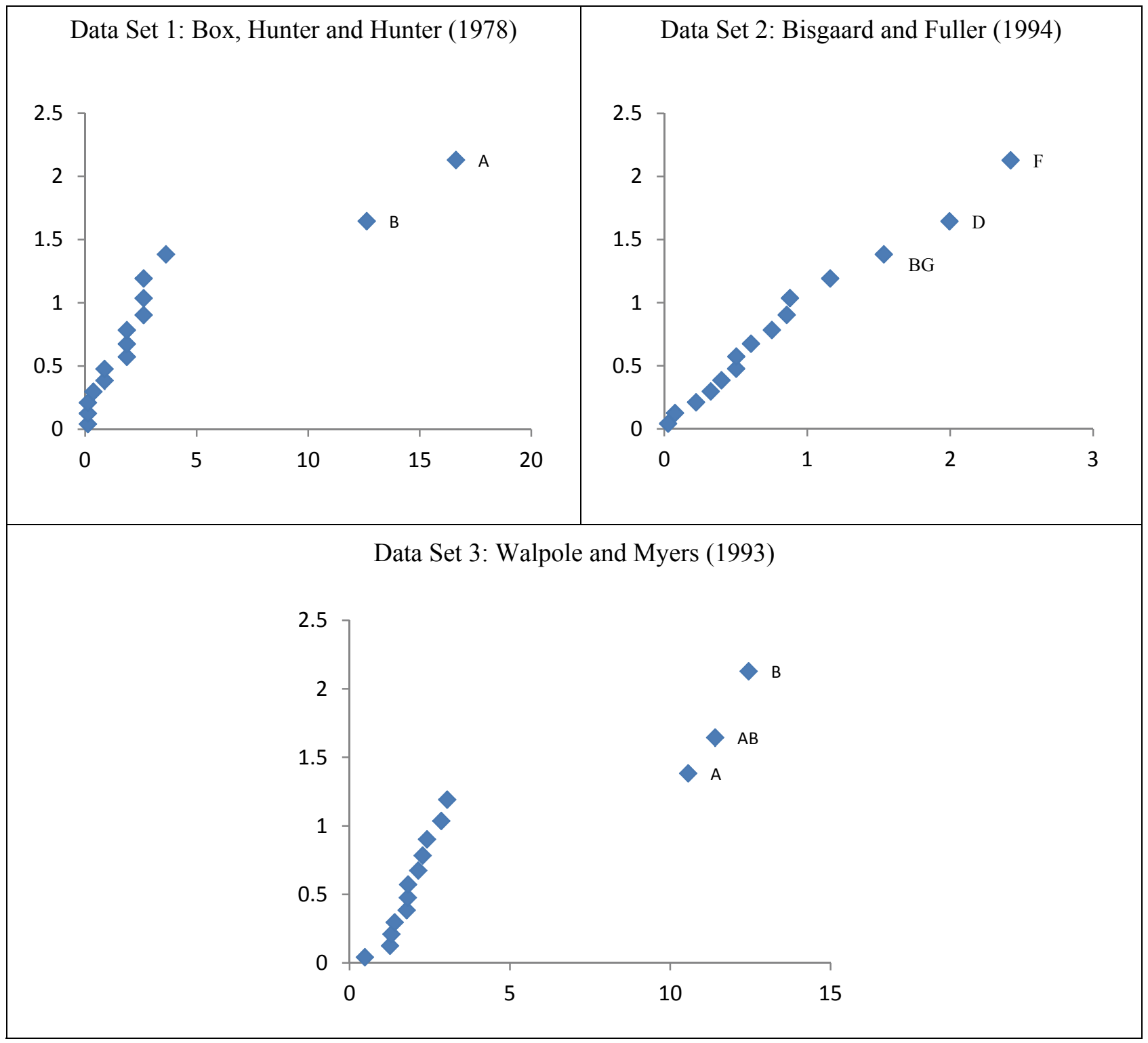

may also be considered active, because the upper confidence limit is very close to zero; this agrees with the results of Bisgaard and Fuller and the half-normal plots. The half-normal plots do not clearly show that $B G$ is active.

Bootstrap Method to Determine Confidence Intervals

Confidence intervals for the mean predicted responses can be obtained as follows: For each effect size determined in step (3) of the bootstrap method, find the predicted value of $Y_{1}$ for the first example, ( $\mathrm{Y}_{2}$ for the second example and $\mathrm{Y}_{3}$ for the third), using the two active factors found for the first example, A and B, and use as coefficients the effect size divided by two. (Note that there are 3 active factors for the second and the third examples). Because the data consists of counts for the first two examples, if the predicted value is negative, zero was substituted for its value. This was necessary for the Bisgaard and Fuller example, however it was not 
necessary for the first and third examples because none of the responses were zero and responses were large positive values. Resampling was repeated 1,000 times, and one thousand predicted values were produced at each setting of the active factors. These 1,000 values were used to construct $95 \%$ confidence intervals for the mean predicted responses. Results are summarized and shown Tables 4-8. Note that, for the first two examples, after finding the confidence intervals for the transformed mean and for the lower and upper confidence limit, the results are un-transformed using a software package that can solve for $x$, when $y$ is known in the equation: $y=(\sqrt{x}+\sqrt{x+1}) / 2$. For the third example, because no transformation was used, the confidence interval provided by the ordinary least squares method is reported.

Table 7 gives the mean predicted values and confidence intervals for the mean predicted values, these results were obtained using the SQL procedure in the statistical software SAS. Re-sampling was repeated 1,000 times. A slight difference occurred between re-sampling 500 and 1,000 times; the length of the confidence interval was slightly smaller when re-sampling 1,000 times. Very little difference was observed between re-sampling 1,000 times and resampling more than 1,000 times.

Table 8 shows the length of the confidence intervals using the different methods for the three different examples. For the Box, Hunter and Hunter example the Bootstrap gave shorter confidence intervals than those of the Generalized Linear Model (GLM). For the Bisgaard and Fuller example, the bootstrap results are not inferior to the untransformed or GLM procedures. For data with count responses where some of the responses are zeros using a transformation is questionable, therefore the bootstrap provides a good alternative. For data such as the third example taken from Walpole and Myers, ordinary least squares (OLS) can be applied and this method results in confidence intervals that are shorter than both the Bootstrap and GLM approaches.

Table 3: Mean Effect Size and Confidence Intervals for the Different Effect Sizes for the Three Different Examples

\begin{tabular}{|c|c|c|c|}
\hline \multirow{2}{*}{ Factors } & \multicolumn{3}{|c|}{ Box Hunter and Hunter } \\
\cline { 2 - 4 } & Mean & LCL & UCL \\
\hline A & 16.82 & 10.75 & 22.50 \\
\hline B & 13.12 & 6.00 & 20.75 \\
\hline C & 0.07 & -10.75 & 10.75 \\
\hline D & 2.59 & -6.75 & 12.50 \\
\hline AB & 1.19 & -10.63 & 13.38 \\
\hline AC & 3.03 & -6.00 & 13.38 \\
\hline AD & 1.69 & -9.00 & 12.25 \\
\hline BC & -2.27 & -11.63 & 7.75 \\
\hline BD & 0.18 & -9.88 & 10.75 \\
\hline CD & 2.75 & -7.00 & 13.00 \\
\hline ABC & -0.04 & -9.75 & 9.25 \\
\hline ABD & -0.60 & -11.50 & 10.38 \\
\hline ACD & -3.64 & -13.13 & 6.13 \\
\hline BCD & 2.11 & -10.00 & 12.63 \\
\hline ABCD & -0.32 & -10.75 & 10.00 \\
\hline
\end{tabular}

\begin{tabular}{|c|c|c|}
\hline \multicolumn{3}{|c|}{ Bisgaard and Fuller } \\
\hline Mean & LCL & UCL \\
\hline-9.16 & -24.63 & 4.38 \\
\hline-1.97 & -17.13 & 15.00 \\
\hline-4.04 & -20.50 & 11.75 \\
\hline-14.97 & -32.50 & -1.13 \\
\hline 0.06 & -16.88 & 16.00 \\
\hline-2.17 & -17.25 & 13.75 \\
\hline 11.58 & -2.38 & 27.50 \\
\hline 10.77 & -2.63 & 26.25 \\
\hline 3.87 & -13.88 & 19.75 \\
\hline 0.55 & -15.75 & 16.25 \\
\hline-11.84 & -28.38 & 0.68 \\
\hline 2.28 & -14.50 & 18.25 \\
\hline 0.88 & -14.88 & 17.00 \\
\hline-16.95 & -32.25 & -3.38 \\
\hline 10.24 & -5.13 & 29.00 \\
\hline
\end{tabular}

\begin{tabular}{|c|c|c|}
\hline \multicolumn{3}{|c|}{ Walpole and Myers } \\
\hline Mean & LCL & UCL \\
\hline 16.82 & 10.75 & 22.50 \\
\hline 13.12 & 6.00 & 20.75 \\
\hline 0.07 & -10.75 & 10.75 \\
\hline 2.59 & -6.75 & 12.50 \\
\hline 11.43 & 2.45 & 20.14 \\
\hline 1.30 & -8.33 & 11.90 \\
\hline-1.67 & -12.09 & 7.86 \\
\hline 2.01 & -8.28 & 12.02 \\
\hline-2.20 & -13.31 & 7.88 \\
\hline 1.45 & -9.30 & 11.11 \\
\hline 2.58 & -5.36 & 12.15 \\
\hline-1.94 & -11.70 & 7.38 \\
\hline-2.99 & -13.07 & 5.32 \\
\hline-0.29 & -10.19 & 9.22 \\
\hline-1.59 & -10.82 & 7.97 \\
\hline
\end{tabular}


Table 4: Results of the Box, Hunter and Hunter (1978) Example

\begin{tabular}{|c|c|c|c|c|c|c|}
\hline \multirow[b]{3}{*}{ Obs. } & \multicolumn{4}{|c|}{ Least Squares } & \multirow{2}{*}{\multicolumn{2}{|c|}{ GLM Poisson }} \\
\hline & \multicolumn{2}{|c|}{ Transformed } & \multicolumn{2}{|c|}{ Untransformed } & & \\
\hline & $\begin{array}{l}\text { Predicted } \\
\text { Value }\end{array}$ & $\begin{array}{c}95 \% \\
\text { Confidence } \\
\text { Interval } \\
\end{array}$ & $\begin{array}{l}\text { Predicted } \\
\text { Value }\end{array}$ & $\begin{array}{c}95 \% \\
\text { Confidence } \\
\text { Interval } \\
\end{array}$ & $\begin{array}{l}\text { Predicted } \\
\text { Value }\end{array}$ & $\begin{array}{c}95 \% \\
\text { Confidence } \\
\text { Interval }\end{array}$ \\
\hline 1 & 7.14 & $(6.92,7.36)$ & 50.42 & $(47.32,53.63)$ & 51.26 & $(42.45,61.9)$ \\
\hline 2 & 8.17 & $(7.95,8.39)$ & 66.26 & $(62.7,69.92)$ & 11.74 & $(8.14,16.94)$ \\
\hline 3 & 7.92 & $(7.7,8.14)$ & 62.22 & $(58.76,65.76)$ & 1.12 & $(0.6,2.08)$ \\
\hline 4 & 8.95 & $(8.73,9.17)$ & 79.67 & $(75.76,83.68)$ & 4.88 & $(2.87,8.32)$ \\
\hline 5 & 7.14 & $(6.92,7.36)$ & 50.42 & $(47.32,53.63)$ & 1.12 & $(0.6,2.08)$ \\
\hline 6 & 8.17 & $(7.95,8.39)$ & 66.26 & $(62.7,69.92)$ & 4.88 & $(2.87,8.32)$ \\
\hline 7 & 7.92 & $(7.7,8.14)$ & 62.22 & $(58.76,65.76)$ & 51.26 & $(42.45,61.9)$ \\
\hline 8 & 8.95 & $(8.73,9.17)$ & 79.67 & $(75.76,83.68)$ & 11.74 & $(8.14,16.94)$ \\
\hline 9 & 7.14 & $(6.92,7.36)$ & 50.42 & $(47.32,53.63)$ & 0.81 & $(0.42,1.56)$ \\
\hline 10 & 8.17 & $(7.95,8.39)$ & 66.26 & $(62.7,69.92)$ & 0.19 & $(0.09,0.38)$ \\
\hline 11 & 7.92 & $(7.7,8.14)$ & 62.22 & $(58.76,65.76)$ & 1.96 & $(1.16,3.3)$ \\
\hline 12 & 8.95 & $(8.73,9.17)$ & 79.67 & $(75.76,83.68)$ & 8.54 & $(5.62,12.98)$ \\
\hline 13 & 7.14 & $(6.92,7.36)$ & 50.42 & $(47.32,53.63)$ & 1.96 & $(1.16,3.3)$ \\
\hline 14 & 8.17 & $(7.95,8.39)$ & 66.26 & $(62.7,69.92)$ & 8.54 & $(5.62,12.98)$ \\
\hline 15 & 7.92 & $(7.7,8.14)$ & 62.22 & $(58.76,65.76)$ & 0.81 & $(0.42,1.56)$ \\
\hline 16 & 8.95 & $(8.73,9.17)$ & 79.67 & $(75.76,83.68)$ & 0.19 & $(0.09,0.38)$ \\
\hline
\end{tabular}


QUMSIYEH \& SHAUGHNESSY

Table 5: Results of Montgomery and Myers (1997) for the Bisgaard and Fuller Example

\begin{tabular}{|c|c|c|c|c|c|c|}
\hline \multirow[b]{3}{*}{ Obs. } & \multicolumn{4}{|c|}{ Least Squares } & \multirow{2}{*}{\multicolumn{2}{|c|}{ GLM Poisson }} \\
\hline & \multicolumn{2}{|c|}{ Transformed } & \multicolumn{2}{|c|}{ Untransformed } & & \\
\hline & $\begin{array}{l}\text { Predicted } \\
\text { Value }\end{array}$ & $\begin{array}{c}95 \% \\
\text { Confidence } \\
\text { Interval }\end{array}$ & $\begin{array}{c}\text { Predicted } \\
\text { Value }\end{array}$ & $\begin{array}{c}95 \% \\
\text { Confidence } \\
\text { Interval }\end{array}$ & $\begin{array}{l}\text { Predicted } \\
\text { Value }\end{array}$ & $\begin{array}{c}95 \% \\
\text { Confidence } \\
\text { Interval }\end{array}$ \\
\hline 1 & 5.50 & $(4.13,6.84)$ & 29.75 & $(16.65,46.41)$ & 51.26 & $(42.45,61.9)$ \\
\hline 2 & 3.95 & $(2.6,5.3)$ & 15.11 & $(6.25,27.65)$ & 11.74 & $(8.14,16.94)$ \\
\hline 3 & 1.53 & $(0.17,2.88)$ & 1.86 & $(* *, 7.78)$ & 1.12 & $(0.6,2.08)$ \\
\hline 4 & 3.07 & $(1.71,4.42)$ & 8.9 & $(2.45,19.04)$ & 4.88 & $(2.87,8.32)$ \\
\hline 5 & 1.53 & $(0.17,2.88)$ & 1.86 & $(* *, 7.78)$ & 1.12 & $(0.6,2.08)$ \\
\hline 6 & 3.07 & $(1.71,4.42)$ & 8.9 & $(2.45,19.04)$ & 4.88 & $(2.87,8.32)$ \\
\hline 7 & 5.49 & $(4.13,6.84)$ & 29.61 & $(16.65,46.41)$ & 51.26 & $(42.45,61.9)$ \\
\hline 8 & 3.95 & $(2.6,5.3)$ & 15.11 & $(6.25,27.65)$ & 11.74 & $(8.14,16.94)$ \\
\hline 9 & 1.07 & $(-0.28,2.42)$ & 0.7 & $(*, 5.41)$ & 0.81 & $(0.42,1.56)$ \\
\hline 10 & -0.47 & $(-1.82,0.89)$ & $*$ & $(*, 0.36)$ & 0.19 & $(0.09,0.38)$ \\
\hline 11 & 1.96 & $(0.6,3.31)$ & 3.34 & $(0.04,10.49)$ & 1.96 & $(1.16,3.3)$ \\
\hline 12 & 3.49 & $(2.14,4.85)$ & 11.7 & $(4.13,23.1)$ & 8.54 & $(5.62,12.98)$ \\
\hline 13 & 1.96 & $(0.6,3.31)$ & 3.34 & $(0.04,10.49)$ & 1.96 & $(1.16,3.3)$ \\
\hline 14 & 3.49 & $(2.14,4.85)$ & 11.7 & $(4.13,23.1)$ & 8.54 & $(5.62,12.98)$ \\
\hline 15 & 1.07 & $(-0.28,2.42)$ & 0.7 & $(*, 5.41)$ & 0.81 & $(0.42,1.56)$ \\
\hline 16 & -0.47 & $(-1.82,0.89)$ & $*$ & $(*, 0.36)$ & 0.19 & $(0.09,0.38)$ \\
\hline
\end{tabular}

*values that can't be calculated using the transformation because of the negative predicted value;

**values that appear to be incorrectly calculated in Montgomery and Myers (1997) work. 
COMPARISON OF RE-SAMPLING METHODS

Table 6: Results of the Walpole and Myers (1993) Example

\begin{tabular}{|c|c|c|c|c|}
\hline \multirow[b]{2}{*}{ Obs. } & \multicolumn{2}{|c|}{ Least Squares } & \multicolumn{2}{|c|}{ GLM Poisson } \\
\hline & $\begin{array}{l}\text { Predicted } \\
\text { Value }\end{array}$ & $\begin{array}{l}95 \% \text { Confidence } \\
\text { Interval }\end{array}$ & $\begin{array}{l}\text { Predicted } \\
\text { Value }\end{array}$ & $\begin{array}{l}95 \% \text { Confidence } \\
\text { Interval }\end{array}$ \\
\hline 1 & 74.20 & $(69.82,78.57)$ & 74.2 & $(66.22,83.14)$ \\
\hline 2 & 73.36 & $(68.98,77.73)$ & 73.36 & $(65.42,82.25)$ \\
\hline 3 & 75.24 & $(70.87,79.61)$ & 75.24 & $(67.2,84.24)$ \\
\hline 4 & 97.21 & $(92.83,101.58)$ & 97.21 & $(88.01,107.36)$ \\
\hline 5 & 74.20 & $(69.82,78.57)$ & 74.2 & $(66.22,83.14)$ \\
\hline 6 & 73.36 & $(68.98,77.73)$ & 73.36 & $(65.42,82.25)$ \\
\hline 7 & 75.24 & $(70.87,79.61)$ & 75.24 & $(67.2,84.24)$ \\
\hline 8 & 97.21 & $(92.83,101.58)$ & 97.21 & $(88.01,107.36)$ \\
\hline 9 & 74.20 & $(69.82,78.57)$ & 74.2 & $(66.22,83.14)$ \\
\hline 10 & 73.36 & $(68.98,77.73)$ & 73.36 & $(65.42,82.25)$ \\
\hline 11 & 75.24 & $(70.87,79.61)$ & 75.24 & $(67.2,84.24)$ \\
\hline 12 & 97.21 & $(92.83,101.58)$ & 97.21 & $(88.01,107.36)$ \\
\hline 13 & 74.20 & $(69.82,78.57)$ & 74.2 & $(66.22,83.14)$ \\
\hline 14 & 73.36 & $(68.98,77.73)$ & 73.36 & $(65.42,82.25)$ \\
\hline 15 & 75.24 & $(70.87,79.61)$ & 75.24 & $(67.2,84.24)$ \\
\hline 16 & 97.21 & $(92.83,101.58)$ & 97.21 & $(88.01,107.36)$ \\
\hline
\end{tabular}


QUMSIYEH \& SHAUGHNESSY

Table 7: Bootstrap Mean and Confidence Interval for the Predicted Values for the Three Examples

\begin{tabular}{|c|c|c|c|c|c|c|}
\hline \multirow[b]{3}{*}{ Obs. } & \multicolumn{6}{|c|}{ Bootstrap (Re-sampling) } \\
\hline & \multicolumn{2}{|c|}{ Box, Hunter and Hunter } & \multicolumn{2}{|c|}{ Bisgaard and Fuller } & \multicolumn{2}{|c|}{ Walpole and Myers } \\
\hline & $\begin{array}{l}\text { Predicted } \\
\text { Value }\end{array}$ & $\begin{array}{l}95 \% \text { Confidence } \\
\text { Interval }\end{array}$ & $\begin{array}{c}\text { Predicted } \\
\text { Value }\end{array}$ & $\begin{array}{l}\text { 95\% Confidence } \\
\text { Interval }\end{array}$ & $\begin{array}{l}\text { Predicted } \\
\text { Value }\end{array}$ & $\begin{array}{c}95 \% \text { Confidence } \\
\text { Interval }\end{array}$ \\
\hline 1 & 50.87 & $(45.39,57.03)$ & 31.86 & $(19.22,45.56)$ & 73.95 & $(66.32,82.06)$ \\
\hline 2 & 65.88 & $(59.29,73.19)$ & 19.19 & $(5.06,33.72)$ & 73.65 & $(66.08,81.29)$ \\
\hline 3 & 61.88 & $(55.57,68.9)$ & 10.26 & $(0,26.78)$ & 75.18 & $(68.45,81.64)$ \\
\hline 4 & 80.12 & $(72.63,88.38)$ & 15.05 & $(3.44,27.34)$ & 97.22 & $(89.44,105.26)$ \\
\hline 5 & 50.87 & $(45.39,57.03)$ & 10.26 & $(0,26.78)$ & 73.95 & $(66.32,82.06)$ \\
\hline 6 & 65.88 & $(59.29,73.19)$ & 15.05 & $(3.44,27.34)$ & 73.65 & $(66.08,81.29)$ \\
\hline 7 & 61.88 & $(55.57,68.9)$ & 31.86 & $(19.22,45.56)$ & 75.18 & $(68.45,81.64)$ \\
\hline 8 & 80.12 & $(72.63,88.38)$ & 19.19 & $(5.06,33.72)$ & 97.22 & $(89.44,105.26)$ \\
\hline 9 & 50.87 & $(45.39,57.03)$ & 3.41 & $(0,15.06)$ & 73.95 & $(66.32,82.06)$ \\
\hline 10 & 65.88 & $(59.29,73.19)$ & 0.07 & $(0,0.91)$ & 73.65 & $(66.08,81.29)$ \\
\hline 11 & 61.88 & $(55.57,68.9)$ & 5.72 & $(0,16.69)$ & 75.18 & $(68.45,81.64)$ \\
\hline 12 & 80.12 & $(72.63,88.38)$ & 17.76 & $(5.44,30.38)$ & 97.22 & $(89.44,105.26)$ \\
\hline 13 & 50.87 & $(45.39,57.03)$ & 5.72 & $(0,16.69)$ & 73.95 & $(66.32,82.06)$ \\
\hline 14 & 65.88 & $(59.29,73.19)$ & 17.76 & $(5.44,30.38)$ & 73.65 & $(66.08,81.29)$ \\
\hline 15 & 61.88 & $(55.57,68.9)$ & 3.41 & $(0,15.06)$ & 75.18 & $(68.45,81.64)$ \\
\hline 16 & 80.12 & $(72.63,88.38)$ & 0.07 & $(0,0.91)$ & 97.22 & $(89.44,105.26)$ \\
\hline
\end{tabular}


COMPARISON OF RE-SAMPLING METHODS

Table 8: Length of Confidence Intervals for the Three Examples Using the Different Methods

\begin{tabular}{|c|c|c|c|c|c|c|c|c|}
\hline \multicolumn{9}{|c|}{ Confidence Interval Length } \\
\hline \multicolumn{2}{|c|}{ Box, Hunter and Hunter } & \multicolumn{3}{c|}{ Bisgaard and Fuller } & \multicolumn{3}{c|}{ Walpole and Myers } \\
\hline Untrans. & GLM & Bootstrap & Untrans. & GLM & Bootstrap & OLS & GLM & Bootstrap \\
\hline 6.31 & 11.64 & 9.44 & 29.76 & 19.45 & 26.34 & 8.75 & 16.92 & 15.75 \\
\hline 7.22 & 13.90 & 11.16 & 21.40 & 8.80 & 27.84 & 8.75 & 16.83 & 15.21 \\
\hline 7.00 & 13.34 & 11.16 & $* *$ & 1.47 & 26.78 & 8.75 & 17.04 & 13.20 \\
\hline 7.92 & 15.75 & 9.44 & 16.59 & 5.45 & 23.91 & 8.75 & 19.35 & 15.82 \\
\hline 6.31 & 11.64 & 9.44 & $* *$ & 1.47 & 26.78 & 8.75 & 16.92 & 15.75 \\
\hline 7.22 & 13.90 & 11.16 & 16.59 & 5.45 & 23.91 & 8.75 & 16.83 & 15.21 \\
\hline 7.00 & 13.34 & 11.16 & 29.76 & 19.45 & 26.34 & 8.75 & 17.04 & 13.20 \\
\hline 7.92 & 15.75 & 9.44 & 21.40 & 8.80 & 27.84 & 8.75 & 19.35 & 15.82 \\
\hline 6.31 & 11.64 & 9.44 & $*$ & 1.13 & 14.25 & 8.75 & 16.92 & 15.75 \\
\hline 7.22 & 13.90 & 11.16 & $*$ & 0.29 & 0.91 & 8.75 & 16.83 & 15.21 \\
\hline 7.00 & 13.34 & 11.16 & 10.45 & 2.14 & 16.69 & 8.75 & 17.04 & 13.20 \\
\hline 7.92 & 15.75 & 9.44 & 18.97 & 7.35 & 24.22 & 8.75 & 19.35 & 15.82 \\
\hline 6.31 & 11.64 & 9.44 & 10.45 & 2.14 & 16.69 & 8.75 & 16.92 & 15.75 \\
\hline 7.22 & 13.90 & 11.16 & 18.97 & 7.35 & 24.22 & 8.75 & 16.83 & 15.21 \\
\hline 7.00 & 13.34 & 11.16 & $*$ & 1.13 & 14.25 & 8.75 & 17.04 & 13.20 \\
\hline 7.92 & 15.75 & 9.44 & $*$ & 0.29 & 0.91 & 8.75 & 19.35 & 15.82 \\
\hline
\end{tabular}

*values that can't be calculated using the transformation because of the negative predicted value; **values that appear to be incorrectly calculated in Montgomery and Myers (1997) work.

\section{Conclusion}

The bootstrap method can be used to determine active factors and to construct confidence intervals for effect size and for a predicted mean response. The results are not inferior to those obtained using transformations or generalized linear models procedures and are actually better in some situations. The availability of computers and statistical software makes using re-sampling (bootstrap) easy and fast and provides good predictions.

\section{References}

Babu, G., \& Singh, K. (1983). Inference on means using the bootstrap. The Annals of Statistics, 11, 999-1003.
Babu, G. J., \& Singh, K.(1984). On one term Edgeworth correction by Efrons bootstrap. Sankhya, 46, Ser.A, 219-232.

Benski, C. (1994). Applicability of nine numerical techniques for detecting active factors in unreplicated experimental designs. ASA Proceedings of the Statistical Computing Section, 214-217. CISid: 154639. Alexandria, VA: American Statistical Association.

Bhattacharya, R. N., \& Qumsiyeh, M. (1989). Second order and Lp- comparison between the bootstrap and empirical Edgeworth expansion methodoligies. Annals of Statistics, 17, 160-169.

Bickel, P. J., \& Freedman, D. A. (1980). On Edgeworth expansions for the bootstrap. Unpublished. 


\section{QUMSIYEH \& SHAUGHNESSY}

Bisgaard, S., \& Fuller, H. (1994). Analysis of factorial experiments with defects or defectives as the response. Quality Engineering, 7(2), 429-443.

Box, G., Hunter, W., \& Hunter, J. (1978). Statistics for experiments. New York, NY: John Wiley.

Daniel, C. (1959). Using of half normal plots in interpreting factorial two-level experiments. Technometrics, 1, 311-341.

Efrom, B. (1979). Bootstrap methods: Another look at jackknife. The Annals of Statistics, 7, 1-26.

Lahiri, S. (1992). Bootstrapping Mestimators of a multiple linear regression parameter. The Annals of Statistics, 20(3), 15481570.

Lenth, R. (1989). Quick and easy analysis of unreplicated factorials. Technometrics, 31, 469-473.

Montgomry, D. and Meyers, R. (1997). A tutorial on generalized linear models. Journal of Quality Technology, 29(3), 274-291.
Qumsiyeh, M. (1994). Bootstrapping and empirical Edgeworth expansions in multiple linear regression models. Communications in Statistical Theory and Methods, 23(11), 32273239.

Qumsiyeh, M., \& Shaughnessy, G. (2008). Using the bootstrap to select active factors in unreplicated factorial experiment. JSM Proceedings, Statistical Computing Section. Alexandria, VA: American Statistical Association.

Qumsiyeh, M., \& Shaughnessy, G. (2010). Bootstrapping un-replicated two-level designs with missing responses. Journal of Statistics, Advances in Theory and Applications, 4, 91-106.

Singh, K. (1981). On the asymptotic accuracy of Efron's bootstrap. The Annals of Statistics, 9, 1187-1195.

Walpole, R. E., \& Myers, R. H. (1993). Probability and statistics for engineers and scientists, $5^{\text {th }}$ Ed. Englewood Cliffs, NJ: Prentice Hall. 